\title{
The Psychology of Patients Infected with COVID 19 in Tunisia during the Treatment Period
}

\author{
Kahna Mohamed*, Cherni Bochra and Baaouni Zaineb \\ University of Tunis ElManar, ESSTST, Tunis, Tunisia \\ *Corresponding Author: Kahna Mohamed, University of Tunis ElManar, Higher \\ School of Health Sciences and Techniques, Tunis, Tunisia..
}

Received: March 27, 2020

Published: April 28, 2020

(C) All rights are reserved by Kahna

Mohamed., et al.

\begin{abstract}
The COVID-19 still causes anxiety and apprehension among many patients today, which can lead to a refusal of care or difficult working conditions. It, therefore, appears prerequisite to set up conditioning and relaxation methods for patients and caregivers to optimize care and working conditions. In this regard, we assess the psychological levels of patients in their forties to detect the factors in order to facilitate the treatment.
\end{abstract}

Keywords: Psychology; Anxiety; Infection; COVID 19

\section{Introduction}

Today, according to the World Health Organization, the world has undergone a sudden transformation after the surge of the Coronavirus pandemic in more than 150 countries. This virus was characterized by its rapid spread among populations [1], which causes multiple emotions: from simple worry to fear, from anxiety to panic attack [2].

And from there, it appears vital to set up methods of conditioning and relaxation for people infected with local COVID 19 in order to optimize care and working conditions. We must work to reduce the psychological pressures of patients infected with Coronavirus during their quarantine and facilitate their treatments.

\section{Methods}

This is a prospective, observational and descriptive study for the evaluation of clinical practice. The first part of the study was conducted through an online survey sent to 30 patients. The objective of the online survey is to collect demographic information, physical symptoms in the past 14 days, contact history with COVID-19, knowledge and concerns about COVID-19, precautionary measures against COVID-19 and other information with respect to COVID-19.

Anxiety, pain and vital signs such as temperature, heart rate and respiratory rate were evaluated and recorded on an observation grid during the treatment period.
We use the Hamilton Anxiety Assessment Scale (HAM-A) to measure the severity of a patient's anxiety [3].

For the secondary endpoints the patients were asked to record pain scores via a paper VAS (visual analog scale) [4] and digitally via both the laptop computer and mobile phone.

Surveillance was put in place regularly throughout the treatment to avoid any adverse reaction to the patient.

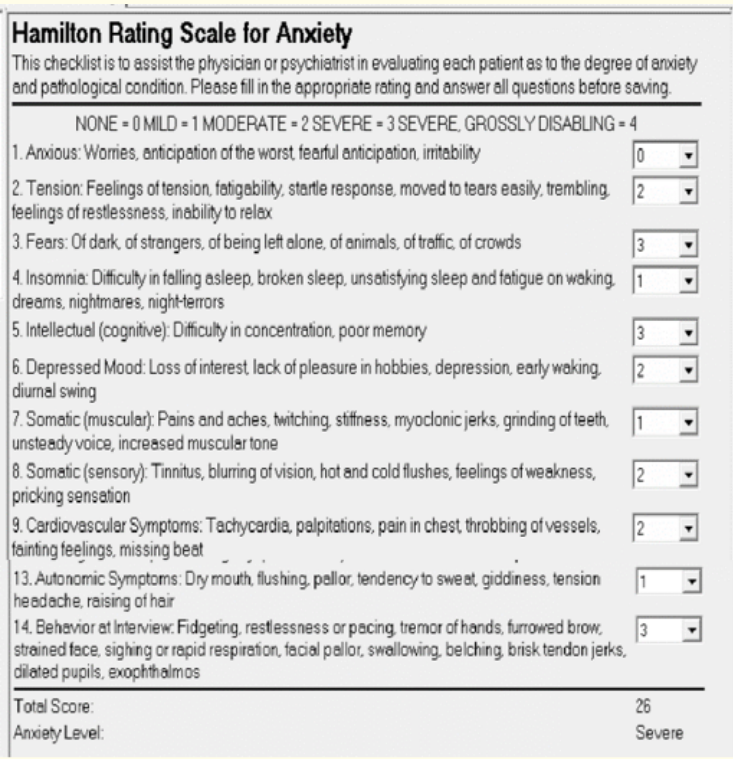

Figure 1: Hamilton anxiety rating scale. 


\section{Results}

During the two-period-month, 32 patients were involved in this study:

- 29 patients performed the entire protocol.

- 3 patients were excluded: 1 due to the change in their quarantine and 2 patients were considered as loss of sight in front of the impossibility of collecting their final data.

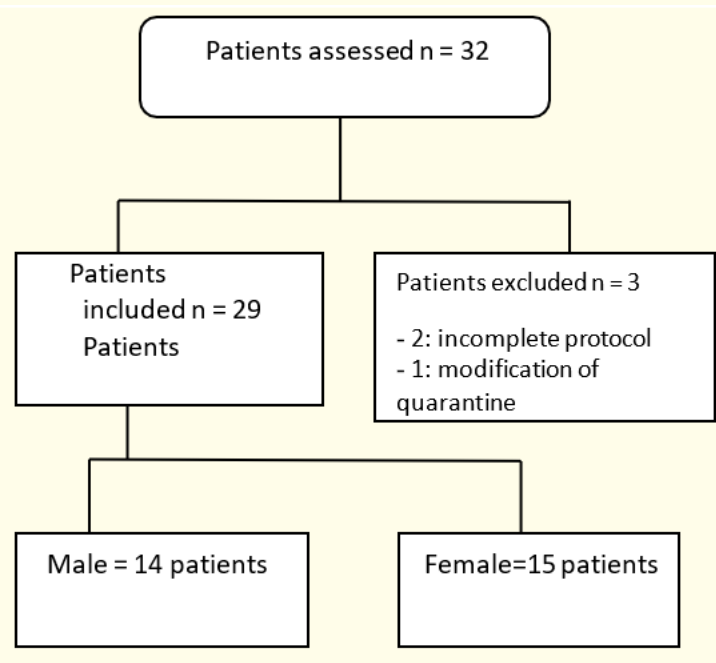

Figure 2: Flow diagram.

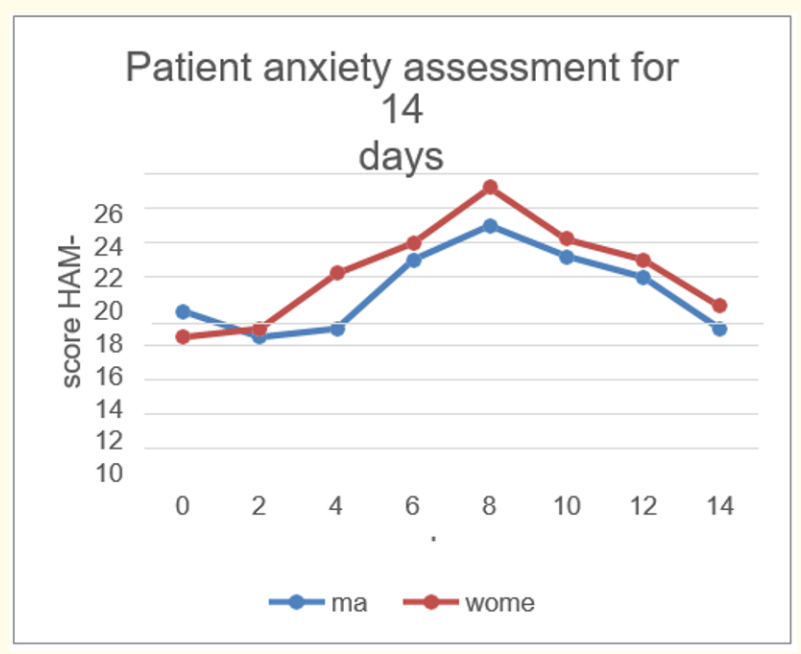

Figure 3: Patient anxiety assessment for 14 days.

The symptoms ranged from mild ones to severe illness and death.

Symptoms could include:

- Fever

- Cough

- Shortness of breath

- $\quad$ Pain in thorax.
The symptoms of COVID-19 may develop within 2 days or during 14 days, after exposure [5].

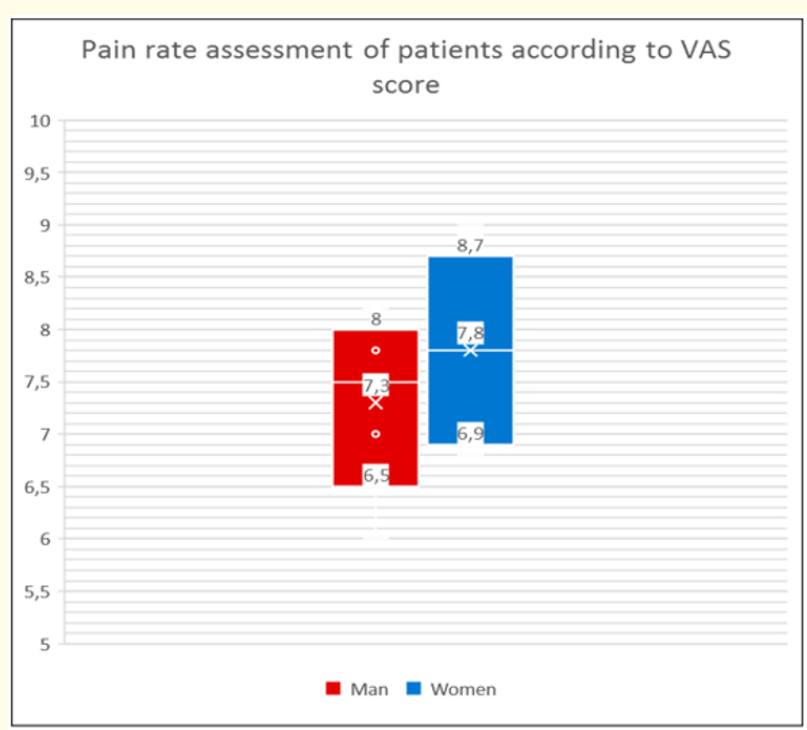

Figure 4: Pain rate assessment of patients according to VAS score.

\begin{tabular}{|l|c|c|c|}
\hline \multicolumn{1}{|c|}{ Variable } & Male & Female & P \\
\hline N (\%) & $14(48.38 \%)$ & $15(51.72 \%)$ & 0.892 \\
\hline Range (years) & & & \\
\hline $20-35$ & $2(14.28 \%)$ & $1(6.66 \%)$ & 0.966 \\
\hline $36-50$ & $4(28.57 \%)$ & $6(40.00 \%)$ & 0.724 \\
\hline $51-65$ & $7(50.00 \%)$ & $4(26.67 \%)$ & 0.822 \\
\hline$>65$ & $1(7.15 \%)$ & $4(26.67 \%)$ & 0.942 \\
\hline Clinical symptoms (\%) & & & \\
\hline Fever & $13(92.85 \%)$ & $15(100 \%)$ & 0.058 \\
\hline $37.3-38.0^{\circ} \mathrm{C}$ & $1(7.69 \%)$ & $2(13.33 \%)$ & \\
\hline $38.1-39.0^{\circ} \mathrm{C}$ & $10(76.92 \%)$ & $9(60.00 \%)$ & \\
\hline$>39.0^{\circ} \mathrm{C}$ & $1(7.69 \%)$ & $4(26.66 \%)$ & \\
\hline Cough & $10(71.42 \%)$ & $12(80.00 \%)$ & 0.687 \\
\hline Fatigue & $12(85.71 \%)$ & $12(80.00 \%)$ & 0.862 \\
\hline Headache & $7(50.00 \%)$ & $10(66.67 \%)$ & 0.6 .88 \\
\hline Hemoptysis & $2(14.28 \%)$ & $3(20.00 \%)$ & 1.000 \\
\hline Diarrhea & $3(21.42 \%)$ & $6(40.00 \%)$ & 0.876 \\
\hline Dyspnea & $4(28.57 \%)$ & $8(53.33 \%)$ & 0.991 \\
\hline Asymptomatic & $1(7.69 \%)$ & $2(13.33 \%)$ & 1.000 \\
\hline
\end{tabular}

Table 1: Use chi square test to compare the demographic and clinical characteristics of the patients.

\section{Discussion}

The objective of this study was to assess the effects of anxiety and pain in patients with COVID-19 in their forties. The main 
results show that patients with this virus have suffered from moderate anxiety which is involved in disturbing their physical signs.

Our results, with regard to the psychological responses of infected patients, suggest that the psychological impact of the pandemic was judged to be moderate or severe; $76.5 \%$ of respondents reported moderate to severe anxiety symptoms; $38.8 \%$ of respondents reported symptoms of moderate to severe pain, and $56.1 \%$ reported moderate to severe stress levels. The prevalence of moderate or severe psychological impact in patients with COVID-19 measured by HAM-A was higher than normal [6].

COVID-infected patients have been at risk of experiencing symptoms of anxiety. It is not clear whether or not the existence of the virus affects the severity of patients' previous psychiatric symptoms. This may be due to the fact that COVID itself can cause progressively extreme symptoms during the 14 days, especially in the 8th day (see curve). This may be due to the way social separation of the quarantine patient decreases social support, which can affect mental and physical prosperity [7]. Likewise, these patients preferred to seek help from family and others and to open up to their well-being due to the isolation $[8,9]$, which reinforces their anxiety and depression.

According to Bereket Duko [10], the content of psychological interventions must be modified to meet the needs of the general population during the epidemic. It should preferably be delivered online or by phone to avoid spreading the infection. Since CBT online does not require the presence of mental health professionals (for example, psychologists), this will be useful to the general public. Based on our results, cognitive therapy can provide information or evidence to build confidence in the doctor's ability to diagnose COVID-19 [11].

Furthermore, in the Zhejiang experiment [12], anxiety and fear were common in patients with COVID-19. They established a dynamic assessment and a warning of psychological crisis. They have also integrated Chinese medicine into treatment to promote the rehabilitation of diseases through classification methods of traditional Chinese medicine and have optimized the nursing process for several patients to promote their rehabilitation to improve prevention, diagnosis and treatment strategies for COVID-19 [12].

\section{Limitations}

This study has several limitations. Given the limited resources available and the time-sensitivity of the COVID- 19 outbreak, we adopted the snowball sampling strategy.

It would also be ideal to conduct a prospective study on the same group of participants after a period. The snowballing sam- pling strategy was not based on a random selection of the sample, and the study population did not reflect the actual pattern of the general population.

As a result, we could not conduct a prospective study that would provide a concrete finding to support the need for a focused public health initiative.

This study provides invaluable information on the initial psychological responses after the outbreak of COVID-19 from patients in Tunisia. Our results could be used as a historical reference. Most importantly, our findings directly inform the development of psychological interventions that can minimize psychological impact, anxiety, depression, and stress during the outbreak of COVID-19 and provide a baseline for evaluating prevention, control, and treatment efforts throughout the remainder of the COVID-19 epidemic, which is still ongoing at the time of preparing this manuscript.

\section{Conclusion}

During the initial phase of the COVID-19 outbreak in Tunisia, more than half of the respondents rated the psychological impact as moderate-to-severe; our findings identify factors associated with a lower level of psychological impact and better mental health status that can be used to formulate psychological interventions to improve the mental health of vulnerable groups during the COVID-19 epidemic.

\section{Bibliography}

1. Wang C. "A novel coronavirus outbreak of global health concern". Lancet 395.10223 (2020): 470-473.

2. Hawryluck L. "SARS control and psychological effects of quarantine, Toronto, Canada". Emerging Infectious Diseases 10.7 (2004): 1206-1212.

3. McDowell I., et al. "Measuring health: a guide to rating scales and questionnaires (Volume 268)". New York: Oxford University Press (2006).

4. UD Reips and F Funke. "Interval level measurement with visual analogue scales in Internet-based research: VAS Generator". Behavior Research Methods 40.3 (2008): 699-704.

5. Chellappan S. "COVID-19: Alerting Health Professionals". Acta Scientific Women's Health 2.4 (2020): 15-17.

6. Rubin GJ and Wessely S. "The psychological effects of quarantining a city". British Medical Journal (Clinical Research Edition) 368 (2020): m313. 
7. Rubin GJ., et al. "The impact of communications about swine flu (influenza A H1N1v) on public responses to the outbreak: Results from 36 national telephone surveys in the UK". Health Technology Assessment 14.34 (2010): 183-266.

8. Cacioppo JT., et al. "Perceived social isolation makes me sad: 5-year cross-lagged analyses of loneliness and depressive symptomatology in the Chicago Health, Aging, and Social Relations Study". Psychology and Aging 25.2 (2010): 453-463.

9. Cacioppo JT., et al. "Loneliness as a specific risk factor for depressive symptoms: cross-sectional and longitudinal analyses". Psychology and Aging 21.1 (2006): 140-151.

10. Duko B., et al. "Depression, Anxiety and Their Correlates Among Patients with HIV in South Ethiopia: An InstitutionBased Cross-Sectional Study". Frontiers in Psychiatry 10 (2019): 290.

11. Sim K. "Psychosocial and coping responses within the community health care setting towards a national outbreak of an infectious disease". Journal of Psychosomatic Research 68.2 (2010): 195-202.

12. Xu K., et al. "[Management of corona virus disease-19 (COVID-19): the Zhejiang experience]". Zhejiang da xue Xue Bao. Yi Xue Ban = Journal of Zhejiang University. Medical Sciences 49.1 (2020).

\section{Assets from publication with us}

- Prompt Acknowledgement after receiving the article

- Thorough Double blinded peer review

- Rapid Publication

- Issue of Publication Certificate

- High visibility of your Published work

Website: www.actascientific.com/

Submit Article: www.actascientific.com/submission.php

Email us: editor@actascientific.com

Contact us: +919182824667 